\title{
Original article (short paper) \\ Building an urban park increases the intention of adults to practice physical activity
}

\author{
Raphaelly Machado Felix \\ Vinicius Martins Farias \\ Mauren Lúcia de Araújo Bergmann \\ Gabriel Gustavo Bergmann \\ Universidade Federal do Pampa, Uruguaiana, RS, Brasil
}

\begin{abstract}
Physical activity levels in adults are low and strategies should be put in place to change this. The aim of this study was to investigate whether building an urban park can increase adult neighborhood residents' intentions to partake in physical activity. In total, 395 adults living near where the park was being built participated in the study. The following information was collected: sociodemographic characteristics, current physical activity levels, and intention to use the park for physical activity. Around $80 \%$ of the subjects intended to use the park for physical activity. This frequency was higher among those who were classified as physically active and gradually higher as the distance between the home of the subject and the park decreased $(p<0.05)$. The offer of a public leisure space can contribute positively to changing population behavior related to regular physical activity.
\end{abstract}

Keywords: physical Activity, leisure activity, urban parks

\section{Introduction}

It has been largely reported that regular practice of physical activity provides health benefits ${ }^{1-5}$. Despite evidence of the benefits of exercise, the prevalence of physical inactivity is high in Brazil and other developed countries, regardless of gender, age, socioeconomic status, and education ${ }^{3}$. Therefore, strategies should be developed to offer the population the opportunity to access and practice physical activity ${ }^{2,3}$.

Urban parks are examples of public spaces that can be used for active recreation. Evidence indicates that the presence of these spaces contributes to increasing the physical activity level of the neighborhood residents $\mathrm{s}^{6,7}$. However, it is important to highlight that the functional and physical characteristics of neighborhood parks can influence the choices and possibilities of leisure of individuals, but do not ensure their use for physical activity ${ }^{8-10}$.

An important characteristic that has been identified is the inverse association between the distance from parks and their use for physical activity ${ }^{11,12}$. Although in Brazil some such efforts are being undertaken, information on this is scarce and mainly derived from large cities: there are no records of studies related to smaller cities ${ }^{13}$. Furthermore, the evidence available is from studies analyzing physical activity in existing urban and neighborhood parks. We have no knowledge of studies that have examined the effects of the construction of new public spaces for leisure on the intention of adults for using it for physical activity. This study investigated if the construction of an urban park with leisure purposes can contribute to increasing the intention of neighborhood residents to practice physical activity regularly.

\section{Methods}

\section{Population and sample}

An analytical observational population-based study was conducted with adult subjects (18-64 years old) from the city of Uruguaiana, Brazil, living in the Ipiranga neighborhood, where the completion of the Sports and Culture Park was expected by April 2015. The park was to be a large public space (1034.46 square meters of built area) with numerous recreational possibilities, including: sports court (indoor); skateboarding facilities; outdoor gym; walking path; running track; playground; table games area; reading areas; and venues for cultural events.

The following characteristics were considered for sampling: a) total neighborhood population of 5,328 individuals aged 18-64 years (Census, 2010); b) 95\% confidence interval (CI $95 \%)$; c) acceptable sampling error of five percentage points; d) prevalence of $50 \%$, and e) $10 \%$ increase to compensate for possible losses and refusals. After the adoption of these criteria, 395 individuals were selected.

The selection process was carried out in a multiphase probabilistic way. The six blocks distributed around the park were considered. All houses in the first block (which are located in parallel streets and facing the park) were selected. In the second block the selection process of the houses took place alternately, i.e., when a house was selected, the house immediately next door was left out of the study, and then the next one was again selected. The procedure was the same for the third, fourth, fifth, and sixth blocks: after selecting the first house, the next two, three, four, and five houses were disregarded, respectively. For the streets perpendicular to the park the selection criteria of the houses was the same as for the parallel streets, i.e., alternately 
and increasing the number of homes not selected as the distance from the park increases. When there was refusal to participate in the study, the house next door was automatically selected, starting the selection procedure of the nearby homes from this house. All individuals meeting the inclusion criteria from the selected households were invited to participate in the study, regardless of the number of people living in each house. The criteria for selecting the first house were: the researcher was positioned in front of the entrance gate of the park, the first house (corner) of the block to the right of the park was selected. This study was reviewed and approved by the Ethics Committee of the Federal University of Pampa (protocol number: 840.171).

\section{Approach}

The houses selected were visited on weekdays and weekends between 14:00 and 20:00. The researchers presented the objectives, procedures, and criteria for participation in the study. The subjects were interviewed after the explanation and the delivery of the free consent terms, receiving their agreement to sign the document and meeting all the inclusion criteria. The inclusion criteria were to reside next to the Sports and Culture Park in Uruguaiana/RS (up to six blocks away) and to be within the age group of interest (18-64 years old). Exclusion criteria were not being able to perform physical activity because of physical disabilities (self-declared) and having any cognitive limitations that made them unable to answer the instrument questions (cognitive limitations characterized as indicated by a relative, guardian or caregiver).

\section{Variables and data collection instruments}

The instrument for data collection consisted of demographic and socioeconomic information, and current practice and intention of practicing physical activity. The demographic information collected was gender (male or female), age (years complete). and distance from the Sports and Culture Park (less than a block away, one, two, three, four, five, or six blocks). Socioeconomic information included family income (number of minimum wages) and education (incomplete primary education, complete primary education, incomplete secondary education, complete secondary education, incomplete higher education and college degree). In order to measure physical activity levels the long version of the International Physical Activity Questionnaire (IPAQ) was used ${ }^{14}$. For the analysis the only information used was from the leisure time physical activity and the results were categorized into two groups: subjects with less than 150 minutes of moderate to vigorous physical activity per week ( $<150$ MVPA) and those with 150 or more minutes of moderate to vigorous physical activity per week ( $\geq 150$ MVPA).

In order to identify the intention of practicing physical activity a tool for behavior change stages was used ${ }^{15}$. Briefly, the individuals who claimed to practice regular physical activity or not (yes or no) were identified. In case of a positive response, whether the practice has being carried out for more or less than six months was ascertained. In case of negative answer, whether there was an intention to begin or not was ascertained. If so, whether there was an intention to begin within the next 30 days or not. In addition, a question of intention to practice physical activity in the Sports and Culture Park (after the completion of its construction) was inserted.

\section{Data analysis}

Variables were initially described using mean and standard deviation (age), and absolute and relative frequencies (other variables) followed by interval confidence of $95 \%$ (IC95\%). To test the possible association between physical activity levels, distance from the park and the intention of using it (after its completion) for the practice of physical activity, the chi-square test was used for heterogeneity and trend, respectively. To test these associations adjusted for sex, age, socioeconomic status. and educational level, binary logistic regression was used. The significance level adopted was 0.05 and all analyses were performed using SPSS software version 20.0.

\section{Results}

The description of the variables analyzed is presented in Table 1. An average age of 42.05 years old was observed, the majority of the sample were female $(64.3 \%)$. and $77.7 \%$ of the subjects were not sufficiently active in leisure activities. Just over one-quarter of the sample stated they were active. However, $78.5 \%$ planned to practice physical activities in the Sports and Culture Park. Many of the samples claimed to live with one minimum wage and more than one-third did not complete elementary school.

Table 1. Description of the variables analyzed from adults aged between 18-65 years, living in the city of Uruguaiana (Brazil) near the Sports and Culture Park.

\begin{tabular}{lcc}
\hline \multicolumn{1}{c}{ Variable } & $\mathbf{N}$ & $\mathbf{\%}(\mathbf{C I 9 5 \% )}$ \\
\hline Gender & & \\
Female & 254 & $64,3(58,4-70,2)$ \\
Male & 141 & $35,7(27,8-43,6)$ \\
\hline Age & 395 & $\mathrm{X}=42,05(\mathrm{SD}=13,880)$ \\
\hline Household income & & \\
\hline Less than one minimum wage & 15 & $3,8(0-13,50)$ \\
One minimum wage & 169 & $42,8(35,3-50,3)$ \\
Two minimum wages & 134 & $33,9(25,9-41,9)$ \\
Three minimum wages & 53 & $13,4(4,2-22,6)$ \\
Four minimum wages & 21 & $5,3(0,43-14,9)$ \\
Five minimum wages or more & 3 & $0,8(0-10,9)$ \\
\hline
\end{tabular}




\begin{tabular}{|c|c|c|}
\hline Variable & $\mathbf{N}$ & $\%(\mathrm{CI} 95 \%)$ \\
\hline \multicolumn{3}{|l|}{ Education level } \\
\hline Incomplete primary education & 155 & $39,2(31,5-46,9)$ \\
\hline Complete primary education & 71 & $18,0(9,1-26,9)$ \\
\hline Incomplete secondary education & 35 & $8,9(0-18,3)$ \\
\hline Complete secondary education & 103 & $26,7(17,6-34,6)$ \\
\hline Incomplete higher education & 17 & $4,3(0-13,9)$ \\
\hline College Degree & 14 & $3,5(0-13,1)$ \\
\hline \multicolumn{3}{|l|}{ Distance between from the park } \\
\hline Less than one block & 47 & $11,9(2,6-21,2)$ \\
\hline One block & 58 & $14,7(5,6-23,8)$ \\
\hline Two blocks & 79 & $20,0(11,2-28,8)$ \\
\hline Three blocks & 57 & $14,4(5,3-23,5)$ \\
\hline Four blocks & 54 & $13,7(4,5-22,9)$ \\
\hline Five blocks & 65 & $16,5(7,5-25,5)$ \\
\hline Six blocks & 35 & $8,9(0-18,3)$ \\
\hline LPA in leisure (IPAQ) & 395 & \\
\hline$<150$ MVPA & 307 & $77,7(73,0-82,4)$ \\
\hline$\geq 150 \mathrm{MVPA}$ & 88 & $22,3(13,6-31,0)$ \\
\hline LPA self-declared & 395 & \\
\hline Inactive & 283 & $71,6(66,3-76,9)$ \\
\hline Active & 112 & $28,4(20,0-36,8)$ \\
\hline
\end{tabular}

\begin{tabular}{lcc}
\multicolumn{3}{l}{ Change of behavior stage } \\
\hline Started for over 6 months \\
\hline Yes & 94 & $83,9(76,5-91,3)$ \\
No & 18 & $16,1(0-33,1)$ \\
\hline
\end{tabular}

\begin{tabular}{lll}
\hline Intend to start in the next months & & \\
\hline Yes & 159 & $53,2(48,5-63,9)$ \\
No & 124 & $43,8(35,1-52.5)$ \\
\hline
\end{tabular}

Intend to start in the next 30 days

\begin{tabular}{lcc}
\hline Yes & 112 & $70,4(61,9-78,9)$ \\
No & 47 & $29,6(16,5-42,7)$ \\
\hline
\end{tabular}

Intend to use the park for physical activity

\begin{tabular}{lcc}
\hline Yes & 306 & $78,5(74,4-82,6)$ \\
No & 84 & $21,5(17,4-25,6)$ \\
\hline
\end{tabular}

$\mathrm{n}$ : absolute number of individuals in each variable and category; \%: relative frequency; CI95\%: confidence interval of $95 \%$.

Table 2 shows the frequency of individuals who intend to use the park for physical activity according to the levels of physical activity in leisure, self-reported physical activity levels, and distance from the park. The frequency of individuals who intend to use the park were significantly higher between those who attending the recommendation for physical activity in leisure (150 minutes or more of MVPA) and who self-reported as active than those who have not reached the recommendation for physical activity and who self-reported as inactive $(p<0.05)$. Regarding the distance from the park, as the distance increases, the frequency of individuals who intend to use it for physical activity decreases $(p<0.05)$.

Table 2. Frequency of individuals who intend to use the park to practice physical activity, according to the level of physical activity in leisure estimated by IPAQ and self-declared, and by the distance from the park.

\begin{tabular}{|c|c|c|c|}
\hline \multirow[b]{2}{*}{ Variável } & \multicolumn{3}{|c|}{$\begin{array}{l}\text { Intend to use the square for physical } \\
\text { activity }\end{array}$} \\
\hline & $\mathbf{N}$ & \% (CI95\%) & $\mathbf{p}$ \\
\hline LPA (IPAQ) & 390 & & 0,010 \\
\hline$\geq 150$ & 87 & $88,5(81,8-95,2)$ & \\
\hline$<150$ & 303 & $75,6(70,8-80,4)$ & \\
\hline LPA self-declared & 390 & & 0,000 \\
\hline Inactive & 279 & $73,8(79,0-68,6)$ & \\
\hline Active & 111 & $90,1(95,7-84,5)$ & \\
\hline Distance from the park & 390 & & 0,030 \\
\hline Less than one block & 47 & $87,2(96,8-77,6)$ & \\
\hline one block & 56 & $83,9(93,5-74,3)$ & \\
\hline two blocks & 79 & $82,3(90,7-73,9)$ & \\
\hline three blocks & 57 & $75,4(86,6-64,2)$ & \\
\hline four blocks & 53 & $67,9(80,5-55,3)$ & \\
\hline five blocks & 64 & $73,4(84,2-62,6)$ & \\
\hline six blocks & 34 & $79,4(93,0-65,8)$ & \\
\hline
\end{tabular}

$\mathrm{n}$ : absolute number of individuals in each level and category; \%: relative frequency of individuals who intend to use the park in each category; CI95\%: confidence interval of $95 \%$; $p$ : value for $p$.

The results from bivariate analysis were confirmed after adjustment for gender, age, education, and household income. Individuals who were most active (estimated by the IPAQ and self-declared) and residing closest to the park had increased odds $(p<0.05)$ relative to the intention of using it for physical activity (Table 3 ). 
Table 3. Adjusted association between the level of physical activity in leisure estimated by IPAQ, the level of self-declared physical activity, distance from the Sport and Culture Park and the intention to use it for physical activity in adults (Uruguaiana/RS, 2014).

\begin{tabular}{lcc}
\hline & & $\begin{array}{c}\text { OR adjusted } \\
\text { (CI95\%) }\end{array}$ \\
\hline LPA (IPAQ)* & & \\
\hline & $\geq 150$ & $2.14(1.03-4.45)$ \\
& $<150$ & 1 \\
\hline LPA self-declared $*$ & Inactive & 1 \\
\hline & Active & $2,95(1,47-5,93)$ \\
\hline $\begin{array}{l}\text { Distance from the park } \\
\text { (raise by the number of blocks) }\end{array}$ & & $0,87(0,76-0,99)$ \\
\hline
\end{tabular}

OR: odds ratio; CI95\%; confidence interval of 95\%; LPA: Level of physical activity; $\geq 150-150$ or more minutes of physical activity of moderate to vigorous intensity per week; $<150$ : less than 150 minutes of physical activity of moderate to vigorous intensity per week; *adjusted for distance from the park, gender, age, education, and family income; **adjusted for level of physical activity in leisure (IPAQ), self-declared level of physical activity, gender, age, education, and family income.

\section{Discussion}

In this study we identified that the construction of an urban park can encourage an increased level of physical activity of the neighborhood residents. The results indicated that most of the subjects, regardless of their current level of physical activity, intended to use the park to practice physical activity after its construction. Furthermore, the distance from the park influenced its use. As the distance increased, the frequency of participants who intended to use it decreased.

These results are considered important as they indicate that the construction of a neighborhood park with spaces and facilities for physical activity increases the chance of inactive individuals to become active and also assists individuals who are active to remain this way. The results corroborate other studies identifying that the construction of urban and neighborhood parks play a key role in facilitating the practice of physical activity ${ }^{11,16}$.

The environmental characteristics appear to influence individual behavior change, including the practice of physical activity ${ }^{7,17-19}$. The existence of parks close to home or within walking distance appears to help make it more attractive for exercising ${ }^{8,20}$.

Although the existence of parks increases the chances for the local population to engage in physical activity, the distance between these and the residences should be considered. Those living further away from parks use them less often and tend to have lower physical activity levels. In this sense, the present study results are in line with those reported by other authors ${ }^{11,12}$. In one of these studies the authors suggest that parks with designated areas for physical activity should be located less than a kilometer away from every residence ${ }^{11}$. This reinforces the hypothesis that the existence of a park nearby is a facilitator for the promotion of physical activity in leisure and reflects directly on discussions about public policies.

Whereas there is currently still little information from studies in Brazil, this study provides an important contribution to a better understanding of the associations between the existence of urban and neighborhood parks and the level of physical activity of adults. However, some possible repercussions about the limitations of this study should be discussed. Physical activity levels were measured with a questionnaire that - while it is an internationally validated instrument used in several studies for this purpose - has limitations due to the subjectivity of the answers, in addition to the interviewee recall bias. The outcome variable of this study, intention to practice physical activity in the park, also brings limitations to the interpretation of the results. It measured the perspective regarding the intention of using the park. However, it did not guarantee that the participants will actually do so. To overcome this limitation, a new study should be conducted after the construction of the park.

In conclusion, urban and neighborhood parks can be facilitators for the practice of physical activity during leisure time. In addition, the proximity of parks is associated with people's intention of using them for physical activity. Joint actions with the government should be planned in order to provide alternatives so that the level of physical activity of the population increases.

\section{References}

1. Harrison RA, Mcelduff P, Edwards R. Planning to win: health and lifestyles associated with physical activity amongst 15, 423 adults. Public Health. 2006; 120:206-212.

2. Sallis J, Cervero RB, Ascher W, Henderson KA, Kraft MK, Kerr J. An ecological approach to creating active living communities. Annu Rev Public Health. 2006; 27:297-322.

3. Lee I-M, Shiroma EJ, Lobelo F, Puska P, Blair SN, Katzmarzyk PT. Effect of Physical Inactivity on Major Non Communicable Diseases Worldwide: an analyses of burden of disease and life expectancy. Lancet. 2012; 380:219-229.

4. Nahas MV, Duca GFD. Atividade física e doenças crônicas: evidências e recomendações para um estilo de vida ativo - 1ed - Florianópolis, UFSC/Núcleo de Pesquisa em Atividade Física e Saúde, 2011.

5. Pucci GC, Rech CR, Fermino RC, Reis RS. Associação entre atividade física e qualidade de vida em adultos: revisão sistemática. Rev. Saúde Pública. 2012; 46:166-79.

6. Kaczynski AT, Henderson KA. Parks and recreation settings and active living: a review of associations with physical activity function and intensity. J Phys Act Health. 2008; 5(4):619-632.

7. Cohen DA, Mackenzie TL, Sehgal A, Williamson S, Golinelli D, Lurie N. Increasing Physical Activity in Parks: Results of a Randomized Controlled Intervention Trial Using CommunityBased Participatory Research. Am J Prev Med. 2013; 45(5):590-597.

8. Santos ES. Reflexões sobre a utilização de espaços públicos para o lazer esportivo. $R A^{\prime} E G A, 2006$; 11:25-33.

9. Silva DAS, Petroski EL, Reis RS. Barreiras e facilitadores de atividades físicas em frequentadores de parques públicos. Motriz, 2009; 15(2):219-227. 
10. Silva MC, Barbosa ASA, Costa TE. Condições de espaços públicos destinados a prática de atividades Físicas na cidade de Pelotas/RS/Brasil. Rev. bras. ativ. fís. saúde. 2012; 17(1):28-32.

11. Cohen DA, Han B, Derose KP, Williamson S, Marsh T, Mackenzie TL. Contribution of Public Parks to Physical Activity. Am J Public Health. 2007; 97 (3):509-514.

12. Mccormack GR, Rock M, Toohey AM, Hignell D. Characteristics of urban parks associated with park use and physical activity: A review of qualitative research. Health Place 2010;16:712-26.

13. Fermino RC, Reis RS, Cassou AC. Fatores individuais e ambientais associados ao uso de parques e praças por adultos de CuritibaPR, Brasil. Rev Bras Cineantropometria Desemp Humano. 2012; 14(4):377-389.

14. Matsudo S, Araújo T, Marsudo V, Andrade D, Andrade E, Oliveira LC et al Questinário internacional de atividade física (IPAQ): estudo de validade e reprodutibilidade no Brasil. Rev Bras Ativ Fís Saúde. 2001; 6(2):05-18.

15. Marcus BH, Banspach SW, Lefebvre RC, Rossi JS, Carleton RA, Abrams DB Using the stages of change model to increase the adoption of physical activity among community participants. Am J Health Promot. 1992; 6:424-429.

16. Hino AAF, Reis RS, Sarmiento OL, Parra DC, Brownson RC. The built environment and recreational physical activity among adults in Curitiba, Brazil. Prev. Med. 2011; 52(6):419-422.

17. Andersen RE, Franckowiak SC, Snyder J, Bartlett SJ, Fontaine KR. Can Inexpensive Signs Encourage the Use of Stairs? Results from a Community Intervention. Ann Intern Med. 1998; 129(5):363-369.
18. Kanh EB, Ramsey LT, Brownson RC, Heath GW, Howze EH, Powell KE, et al. The effectiveness of interventions to increase physical activity. A systematic review. Am J Prev Med.2002; 22:73-107.

19. Petroski EL, Silva DAS, Reis RS, Pelegrini A. (Estágios de mudança de comportamento e percepção positiva do ambiente para atividade física em usuários de parque urbano. Motricidade. 2009; 5(2):17-31.

20. Bedimo-Rung AL, Mowen AJ, Cohen DA. Activity and public health: A conceptual model. Am J Prev Med. 2005; 28:159-168.

\section{Corresponding author}

Gabriel Gustavo Bergmann

Address: UNIPAMPA - Campus Uruguaiana

Email: gabrielbergmann@unipampa.edu.br

Manuscript received on February 25, 2016

Manuscript accepted on May 08, 2016

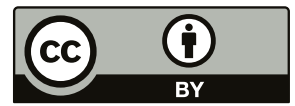

Motriz. The Journal of Physical Education. UNESP. Rio Claro, SP, Brazil - eISSN: 1980-6574 - under a license Creative Commons - Version 3.0 